\title{
TRANSMISSÃo PSíQUICA ENTRE AS GERAÇÕES
}

\author{
Olga B. Ruiz Correa 1 \\ Membro Efetivo da Societé Française de Thérapie Familiale Psychanalytique
}

\begin{abstract}
O reconhecimento da alienação da subjetividade, comprometida numa transmissão psíquica geracional defeituosa, possibilita um novo olhar clínico sobre as patologias da modernidade. O vínculo mãe-bebê e o grupo familiar constituem o berço psíquico do sujeito, constituído por uma tecelagem grupal geracional que poderíamos denominar arquivos de família. Os processos de transmissão são sustentados por mecanismos de identificação junto a um interjogo de projeções-introjeções $e$ incorporações, assim como por uma referência ao superego parental. Neste espaço psíquico intersubjetivo se processa a transmissão psíquica geracional, que precisa ser metabolizada e sofrer transformações. Na clínica do grupo familiar são considerados os traços traumáticos $e$ feridas narcisistas que são transmitidos como restos do "negativo", sem modificação e de forma repetitiva, nos diversos vínculos do espaço grupal-familiar, gerando, assim, diversos sintomas e sofrimento intra e intersubjetivo.
\end{abstract}

Descritores: Gerações. Subjetividade. Psicanálise.

$\mathrm{O}$ reconhecimento da alienação da subjetividade comprometida numa transmissão psíquica defeituosa possibilita um novo olhar clínico sobre as patologias da modernidade.

$\mathrm{O}$ vínculo mãe-bebê e o grupo familiar constituem o berço psíquico do sujeito, constituído por uma tecelagem psíquica grupal que atravessa outras gerações. Os processos de transmissão solicitam um importante trabalho

1 Psicanalista, Psicoterapeuta de casal e família, Membro Efetivo da Societé Française de Thérapie Familiale Psychanalytique e da Societé Française de Psychothérapie Psychanalytique de Groupe, Paris. Endereço eletrônico: olgarcorrea@ terra.com.br 
psíquico no qual participam mecanismos de identificação junto a uma série de projeções-introjeções. Sua problemática atravessa e opera sobre o recalque e a culpa, envolvendo diversas categorias de interdição.

Nos textos de Freud, a palavra alemã ubertragung define a transmissão ou transmissibilidade. Este termo aponta para o sentido de transferência na psicanálise, incluindo, entre outros, o significado de tradução. Este é um ponto central do importante trabalho psíquico da subjetividade, o de retradução e transformação de uma geração a outra das diversas configurações de objetos psíquicos que constituem a pré-história do sujeito. No dispositivo do tratamento psicanalítico, a transmissão está intimamente ligada à transferência e à repetição.

As mudanças nos sistemas de transmissão psíquica e socioculturais, assim como suas fissuras, colocam em primeiro plano a polaridade negativa da transmissão, aquilo que fica oculto, não dito ou "mal dito", atravessando as gerações na dimensão do transgeracional. Quando é marcada pelo negativo, observamos que o que se transmite é aquilo que não pode ser contido, o que não encontra inscrição no psiquismo dos pais é depositado no psiquismo da criança: os lutos não realizados, os objetos desaparecidos sem traço nem memória, a vergonha, as doenças e a falta.

Estas questões atravessam o interesse teórico clínico da psicanálise francesa nos últimos 30 anos, liderada pelas importantes contribuições do professor Kaës e outros colegas como Mijolla, Enriquez, Rouchy e Eiguer, para mencionar só alguns entre os pesquisadores mais representativos.

Assinalamos, como referência prévia e fundamental ao tema, alguns dos trabalhos precursores de Freud nos quais ele desenvolve em diversos registros esta problemática em torno das bases narcisistas e dos processos identificatórios. Sua hipótese sobre a transmissão é fundamentalmente filogenética.

Em Introdução ao Narcisismo, Freud (1914/1973) assinala uma continuidade na vida psíquica entre gerações, reforçando questões já esboçadas em Totem e Tabu (1913/1973), considerando que o sentimento de culpa se constitui em organizador da cultura, e apontando a dimensão do assujeita- 
mento a uma corrente geracional como elo da transmissão, o que já evidencia uma preocupação pelo contexto da intersubjetividade na vida psíquica individual.

Nessa obra, Freud (1914/1973), desenvolve a atribuição de lugares e os significantes presentes no processo de transmissão em que "sua majestade o bebê" é o herdeiro dos sonhos e desejos não realizados pelos seus pais, ponto crucial a partir do qual o sujeito deve, em seu processo de subjetivação, assumir seu lugar e apropriar-se do sentido de seu próprio desejo, em relação ao desejo de seus predecessores.

Em 1920, o modelo especulativo da função do Outro fica delineado em Psicologia das Massas e Análise do Ego, a partir da permuta do Ideal do Ego individual com um objeto ideal comum, com identificações imaginárias compartilhadas. Estas identificações constituem a base narcísica do sentimento de pertença grupatcomunitário.

O processo de transmissão entre as gerações sustenta valores, crenças e diversos saberes que asseguram a continuidade grupal e cultural como a tradição, assinala Freud, porém, esta transmissão direta foi considerada ins uficiente como resposta para a questão da continuidade da vida psíquica entre as gerações.

As contribuições de Abraham e Torok (1978), psicanalistas de origem húngara, contém conceitos chaves para as futuras elaborações neste campo de pesquisa. A definição de cripta refere-se ao enterro intrapsíquico de uma vivência vergonhosa e indizível, traduzindo-se num fantasma de incorporação, sendo este o resultado dos efeitos de um segredo inconfessável. O sujeito portador de uma cripta é levado a simbolizar em relação a um outro presente em si, sob a forma de um objeto psíquico interno, num estado de "morto vivo".

Os novos desenvolvimentos sobre a introjeção frustrada em torno dos estados patológicos de luto, traumatismos não elaborados, assim como os diversos percursos do sofrimento narcisista, possibilitaram novas leituras clínicas de complexas patologias, tais como os estados "borderline" e distúrbios psicossomáticos. Ambos os autores têm conceitualizado a partir da clí- 
nica, tendo como pano de fundo as situações traumáticas e a presença constante da pulsão de morte, atravessando gerações no processo da transmissão.

Abraham assinala nos seus estudos sobre o fantasma, seu estatuto do intraduzível. Para este autor as lacunas no ego a partir do fantasma se assemelham a uma chaga aberta que o sujeito procura camuflar. $\mathrm{O}$ universo do fantasma se traduz, às vezes, em narrativas fantásticas que se aproximam do que Freud descreve como "inquietante estranheza".

Abraham descreve o fantasma como uma sombra, tratando-se de uma formação do inconsciente com a particularidade de nunca ter sido consciente, e decorrendo da passagem do inconsciente de um dos pais para o inconsciente do filho de maneira intrusiva, com uma função diferente do recalcado dinâmico; assim, o fantasma transmitido ao filho encerra aquilo que, para o pai ou para a mãe, teve valor de ferida ou catástrofe narcisista. Nessa hipótese, fica evidente que, na cripta, existe um trabalho psíquico vinculado à pulsão de morte, postulada por Freud na segunda teoria das pulsões.

Abraham e Torok (1978) salientaram o vínculo social como suporte do fato psíquico individual, assinalando também o movimento contínuo do sujeito na recriação de si próprio (processo de subjetivação) e na procura de sentido.

Alguns sintomas da patologia e do sofrimento psíquico estão referidos a falhas nos apoios da vida pulsional, quando o sujeito desenvolve formações psíquicas clivadas que interferem na formação dos processos de incorporação de objetos internos seguros, nos quais ele pode confiar, envolvendo em particular a relação precoce mãe-bebê.

O processo de transmissão psíquica geracional solicita um trabalho psíquico inconsciente constante, de elaboração e transformação. Este processo é definido como obrigatório na sucessão das gerações, porém, a urgência não é sempre a de realizar a transmissão, mas também a de interrompê-la.

Esta transmissão está referida a objetos psíquicos constituídos pelas diversas modalidades identificatórias, assim como os fantasmas que organizam a representação interna dos vínculos. A questão mais significativa é que se transmite o sentido das situações, podendo ser o negativo ou o não reve- 
lado traduzido como falta de sentido. Neste caso, a transmissão salienta especialmente que, o que fica enigmático, são os objetos perdidos, recalcados ou não integrados pelo sujeito, envolvendo, assim, as falhas nos processos de simbolização.

O grupo familiar é um espaço psíquico comum (intersubjetividade) que possibilita a passagem da transmissão psíquica entre as gerações através de diversas modalidades. Este espaço é delimitado por um envoltório de essência genealógica que se processa em contínua evolução, podendo ser modificado pelos acontecimentos internos ao grupo, pelas diversas crises vitais e acontecimentos tais como nascimentos, separações, mortes etc.

Na clínica, deparamo-nos com núcleos psicóticos em crianças nascidas durante um luto materno impossível, tal como a morte de um filho. $\mathrm{O}$ novo vínculo se sustenta, às vezes, na experiência de "não vínculo ou não sentido" transmitido na relação com o filho, ficando ele, exposto à ameaça de morte psíquica.

M. Enriquez tem desenvolvido, a partir de suas pesquisas, a hipótese do delírio parental em herança, numa tentativa de procura de sentido. Assinalou o processo pelo qual a criança, ao ser confrontada ao discurso delirante parental, deverá gerenciar da melhor forma possível a complexidade desta violência que lhe é imposta, para não ficar esmagada por ela. Trata-se, a miúde, de um discurso acusador, culposo ou megalomaníaco, trazendo embutido uma interpretação dos diversos enigmas que são, para todos e cada um, a origem da vida, da morte, do desejo e da sexualidade.

\section{Aspectos da intersubjetividade}

Uma das novas perspectivas abertas na pesquisa desta problemática é a de uma reflexão sobre as exigências do trabalho psíquico intra e intersubjetivo imposto pela sua inscrição no geracional e na intersubjetividade, num cenário que inclui uma violência de ordem, intensidade e origem diversa. 
Esta violência se perfila, às vezes, com altos custos nos percursos do desejo e na construção da subjetividade.

A clínica psicanalítica obteve novos modelos de compreensão, neste campo, por meio dos desenvolvimentos do Professor Kaës, articulados com os de P. Aulagnier, para trabalhar a problemática do vínculo intersubjetivo como fundamento da vida psíquica, a partir de pesquisas do grupo em situação psicanalítica, da experiência da clínica com psicóticos e da cura psicanalítica. Esta questão envolve a formação do psiquismo (sua dimensão grupal) na construção do sujeito e do Eu. Não encontramos uma teoria do sujeito em Freud, porém, ele concebe uma "pluralidade de pessoas psíquicas".

Apesar desta preocupação inaugural e permanente da obra de Freud em torno da intersubjetividade, esta questão ficou pouco definida ou ambígua na psicanálise, na medida em que não foi construída como um conceito teórico psicanalítico propriamente dito.

No campo da psicanálise coexistem diversas teorias do sujeito. Em Lacan, trata-se da teoria do sujeito assujeitado ao desejo do Outro, em particular ao seu discurso. Quando Lacan propõe uma teoria da intersubjetividade, refere-se aos efeitos da intersubjetividade sobre o sujeito e não à questão da consistência psíquica do vínculo intersubjetivo.

A partir do espaço narcísico em que se encontram as gerações, P. Aulagnier elabora o conceito de contrato narcisista, assinalado como noção fundamental para toda tentativa de articular a intersubjetividade como problemática psicanalítica. A questão da transmissão psíquica entre as gerações envolve processos que desorganizam o espaço intrapsíquico e o da intersubjetividade. Esta questão levanta o problema do reconhecimento e da articulação de dois espaços psíquicos, parcialmente heterogêneos, com lógicas que lhe são próprias.

O tecido vincular do grupo familiar é permeado pelas alianças e pactos inconscientes envolvendo a intersubjetividade, assim como pelo contrato narcisista assinalado (Aulagnier, 1975). Trata-se de um acordo inconsciente que assegura a continuidade do investimento libidinal de autoconservação para cada sujeito e o conjunto (familiar-social) do qual forma parte. A crian- 
ça, desde sua vinda ao mundo, é requerida para compartilhar os enunciados dos ancestrais, assegurando a continuidade geracional e a identidade familiar, às vezes, ao custo de sua integridade psíquica e até mesmo somática, já que estes enunciados poderão contradizer suas próprias percepções internas e externas.

O pacto denegativo formulado pelo Prof. Kaës descreve o trabalho do inconsciente necessário à formação do vínculo intersubjetivo nas condições que servem ao recalque ou à denegação dos sujeitos envolvidos.

Estes contratos intersubjetivos são organizadores do vínculo, tendo uma função defensiva, ao mesmo tempo em que são a garantia de um espaço que possibilita o desenvolvimento da subjetividade.

A temporalidade da transmissão psíquica não é fluida, conservando-se pelos traços. Nos modelos de transmissão, traço se opõe a fluido. A memória do afeto e da representação constitui um traço que poderá seguir um destino no inconsciente, mantendo-se ativa além do recalque e da consciência do sujeito.

\section{Traumatismos acumulativos}

O silêncio da violência ou ruptura dos diversos vínculos geracionais, assim como os mecanismos da repetição, constituem o denominador comum que percorre a falta de inscrição do sujeito na sucessão das gerações e no tecido grupal comunitário, limitando ou impedindo o acesso aos processos de simbolização que organizam uma cadeia de significantes. Uma referência significativa na clínica é a intensidade do sofrimento psíquico dos refugiados ou familiares de desaparecidos, no período da ditadura latino-americana ou do Holocausto no período nazista, re-traduzidos no silêncio do indizível vinculado a vivências da ordem da psicose.

A urgência de gerenciar a fratura dos vínculos geracionais e sociais leva a defesas específicas do tipo denegação, clivagem, identificação proje- 
tiva, ou seja, mecanismos que tendem a minimizar ou eliminar o elemento traumático.

Observamos, na clínica, que é nesta articulação que se constroem formações da ordem do segredo, ficando como herança para as futuras gerações.

A noção de traumatismo acumulativo é uma hipótese válida como pano de fundo da patologia transgeracional ligada, na sua origem, à eclosão de vínculos intra, inter e trans-subjetivos originados em diversas situações de violência.

Lembramos que a transmissão psíquica geracional acontece através de:

1) imagens psíquicas originadas na vida libidinal do sujeito e alimentadas pelas experiências dolorosas dos pais ou ascendentes;

2) censura e segredos não traumáticos inicialmente, mas que assim se tornam pela confluência de diversas situações.

A palavra traumatismo tem sido utilizada originariamente em medic ina e cirurgia. O termo retomado por Freud refere-se, em psicanálise, ao choque violento ou a um acontecimento intenso na vida do sujeito, pelo qual o mesmo é incapaz de reagir de forma adequada, produzindo um desbordo emocional que provoca efeitos patogênicos duráveis na organização psíquica. Fica assim definido o acento na dimensão econômica do fluxo da excitação em relação à capacidade de tolerância do aparelho psíquico.

A angústia, derivada de um excesso de excitação provocada pelo acontecimento traumático e a incapacidade de contê-lo, transformando-o em experiência metabolizada, provocará necessariamente desorganizações æecundárias, efração dos envoltórios individuais e grupais, aumentando a violência nos diversos espaços psíquicos.

A importância do reconhecimento do campo da realidade do objeto, na situação traumática, tem sido um fato marcante observado na clínica com pacientes e famílias em TFA (terapia familiar analítica), com sofrimentos vinculados a diversas ordens de violência, a situações da ordem de catástrofe social importantes, que ocasionaram falhas nos processos de simbolização e na inscrição geracional. 
Encerrando, menciono alguns elementos para a reflexão de questões que, certamente, serão desenvolvidas ao longo do simpósio e que se articulam nos diversos espaços psíquicos envolvidos na transmissão entre as gerações.

Em experiências da ordem dos genocídios como o da Armênia, o da Shoah, os acontecidos recentemente na Bósnia, ou de outra ordem de intensidade nas violentas repressões ocorridas na América Latina nos períodos da ditadura, deparamo-nos com uma conjunção de fissuras das denominadas garantias meta-sociais que produzem efeitos metapsíquicos, ao mesmo tempo em que se produzem fraturas importantes nos vínculos inter-subjetivos que sustentam a transmissão psíquica geracional, tendo como base a angústia não metabolizada.

Além da violência intrapsíquica que pode alcançar um nível psicótico, superpõe-se uma outra violência, de nível social, quando a realidade traumática é denegada pela Sociedade, a partir do contexto grupal comunitário e de suas instituições (tal a dúvida da existência dos fornos crematórios em diversos países da Europa, no período nazi-fascista ou a realidade da tortura e de desaparecidos no período das ditaduras latino-americanas). A falta do reconhecimento do traumatismo real produz uma violência enlouquecedora.

As garantias meta-sociais que foram mencionados são matrizes de simbolização da cultura, valores, e tudo aquilo que constitui referências de sentido e que foi obtido a partir do trabalho da civilização assinalado por Freud. Nas situações de violência ou catástrofe social, o sujeito, o grupo familiar e os apoios grupais/comunitários ficam ameaçados pela própria fragilidade e pela ausência destas referências de significação através de suas instituições mediadoras (família, organizações educativas e laborais). Estas instituições constituem envoltórios psíquicos grupais (Anzieu) que agem como continentes e que, habitualmente, permanecem silenciosos. O processo de transmissão entre as gerações permanece, então, comprometido, desafiando uma nova re-inscrição no elo geracional. Os novos dispositivos de trabalho psicanalítico, como a TFA (terapia familiar psicanalítica), contrib uem para abordar o indizível ou impensável provocado nestas conjunções que sustentam uma superposição de traumatismos, os quais, certamente, deixa- 
ram traços nas diversas gerações envolvidas, solicitando um trabalho de metabolização que possibilite a criatividade e a transformação. Isto significa devolver ao sujeito sua capacidade de pensar-se como um "eutsingular", dentro da trama inter-subjetiva da história familiar.

Ruiz Correa, O. B. (2003). Psychic transmission between generations. Psicologia USP, 14(3), 35-45.

Abstract: The recognition of the alienation of subjectivity, compromised by a defective generational psychic transmission, makes way to a fresh clinical look into the pathologies of Modernity. The mother-baby bond, as well as the family group, constitute a psychic cradle for the subject; it is constituted by a generational group weaving that could be called 'family archives'. The transmission processes are sustained by identification mechanisms within an interplay of projections-introjections and incorporations, as well as by a reference to the parental superego. The generational psychic transmission that needs to be metabolized and undergo transformations takes place within the bounds of this intersubjective psychic space. The traumatic traces and narcissistic wounds which are transmited as remainders of the "negative", without modification and repetitively, in the various bonds of the family group space, are taken into consideration in family group practice. These traces and wounds are responsible for a number of symptoms as well as intra and intersubjective suffering.

Index terms: Generations. Subjectivity. Psychoanalysis.

Ruiz Correa, O. B. (2003). Transmission psychique entre générations. Psicologia USP, 14(3), 35-45.

Résumé: La reconnaissance de l'aliénation de la subjectivité, compromise par une transmission psychique entre générations défectueuse permet un nouvel examen clinique sur les pathologies de la modernité. Le lien mèreenfant et le groupe familial constituent le berceau psychique du sujet; il est constitué d'un tissu de groupes inter générations qu'on pourrait appeler 


\section{Transmissão Psíquica entre as Gerações}

archives familiales. Les processus de transmission sont soutenus par des mécanismes d'identification joint à un jeu de projection-introjection et incorporations, comme par une référence au super ego parental. Dans cet espace psycho-intersubjectif se créé la transmission psychique entre générations qui doit être métabolisée et souffrir des transformations. Dans la clinique du groupe familial, on tient compte des traces traumatiques et des blessures narcissiques qui sont transmises comme les restes du « négatif », sans modification et de forme repetitive, dans les divers liens de l'espace groupe-famille, créant ainsi divers symptômes et souffrances intra et intersubjectifs.

Mots-clés: Générations. Subjectivité. Psychanalyse.

\section{Referências}

Abraham, N., \& Torok, M. (1978). A casca e o núcleo. São Paulo: Escuta.

Freud, S. (1920). Mas allá del principio del placer. In S. Freud, Obras completas (Vol. 19). Buenos Aires, Argentina: Amarrortu.

Freud, S. (1973). Malaise dans la civilisation. Paris: PUF. (Trabalho original publicado em 1929)

Freud, S. (1973). Pour introduire le narcissisme. Paris: PUF. (Trabalho original publicado em 1914)

Freud, S. (1973). Totém et tabú. Paris: PUF. (Trabalho original publicado em 1913)

Kaës, R. (1993). Transmission de la vie psychique entre les générations (em Le sujet de l'heritáge). Paris: Dunod.

Kaës, R. (1994). La parole et le lien. Paris: Dunod.

Ruiz Correa, O. (2000). O legado familiar. Rio de Janeiro: Contracapa.

Ruiz Correa, O. 2001). Os avatares da transmissão psíquica geracional. São Paulo: Escuta.

Recebido em 11.02.2004

Aceito em 11.03.2004 